\title{
Freedom from discrimination or freedom to discriminate? Discursive tensions within discrimination policies in medical education
}

\author{
Javeed Sukhera ${ }^{1}$ (D) Helly Goez ${ }^{1,2} \cdot$ Allison Brown $^{1,3}$ (D) Wael Haddara ${ }^{1,4}$. \\ Saleem Razack ${ }^{1,5}$ (D)
}

Received: 23 April 2021 / Accepted: 5 January 2022 / Published online: 13 January 2022

(c) The Author(s), under exclusive licence to Springer Nature B.V. 2022

\begin{abstract}
The importance of advancing equity, diversity, and inclusion for all members of the academic medical community has gained recent attention. Academic medical organizations have attempted to increase broader representation while seeking structural reforms consistent with the goal of enhancing equity and reducing disproportionality. However, efforts remain constrained while minority groups continue to experience discrimination. In this study, the authors sought to identify and understand the discursive effects of discrimination policies within medical education. The authors assembled an archive of 22 texts consisting of publicly available discrimination and harassment policy documents in 13 Canadian medical schools that were active as of November 2019. Each text was analysed to identify themes, rhetorical strategies, problematization, and power relations. Policies described truth statements that appear to idealize equity, yet there were discourses related to professionalism and neutrality that were in tension with these ideals. There was also tension between organizations' framing of a shared responsibility for addressing discrimination and individual responsibility on complainants. Lastly, there were also competing discourses on promoting freedom from discrimination and the concept of academic freedom. Overall, findings reveal several areas of tension that shape how discrimination is addressed in policy versus practice. Existing discourses regarding self-protection and academic freedom suggest equity cannot be advanced through policy discourse alone and more substantive structural transformation may be necessary. Existing approaches may be inadequate to address discrimination unless academic medical organizations interrogate the source of these discursive tensions and consider asymmetries of power.
\end{abstract}

Keywords Discrimination · Harrassment · Racism · Policy · Mistreatment · Professionalism

Extended author information available on the last page of the article 


\section{Introduction}

Recent events have catalyzed a process of reflection and change for academic medicine. The racial disparities exposed by the COVID 19 pandemic, the death of Joyce Echaquan in a Canadian hospital, the murder of George Floyd in the United States of America, and the subsequent Black Lives Matter protests have served to highlight the pervasive role of societal inequities in the lives and health of racialized people. In this context, calls for action to improve equity, diversity, inclusion (EDI) in medical education have become increasingly urgent (Ross et al., 2020). Equity refers to constantly and consistently recognizing and redistributing power, diversity refers to ensuring multiple identities are represented within an organization, while inclusion refers to working to ensure that thoughts, ideas, and perspectives of all individuals matter (Pacific University Oregon, n.d.; Canadian Medical Association, 2020).

The results of existing efforts have been mixed. Although there has been some success in diversifying admissions for select demographics, research suggests that previous efforts to advance EDI have been insufficient to achieve structural reforms and sustainable change to workplace cultures (Canadian Medical Association, 2020; Khazanchi et al., 2021). For example, mistreatment and discrimination are disproportionately experienced by individuals who are minoritized whether on the basis of race, sex/gender or Indigenous status. Students from the aforementioned groups experience less supportive social and less positive learning environments, which can worsen psychological distress and impair performance (Orom et al., 2013; Perry et al., 2016; Bullock et al., 2020; Sheehan et al., 1990). Challenges with EDI extend beyond the student body with academic medical organizations continuing to grapple with difficulties challenges in both faculty recruitment and retention (Price et al., 2005).

Historically, educational institutions have utilized policy as a mechanism for reporting and addressing discrimination and harassment in learning and working environments (National Academies of Science, Engineering, and Medicine, 2018; Jones \& Nichols, 2020). For example, policy can provide a mechanism to address racial disparities and improve diversity through changes in recruitment while addressing workplace discrimination through procedures for reporting and addressing complaints (Kromydas, 2017; Jones \& Nichols, 2020). Nevertheless, the effectiveness of such policies has been questioned. In one context, despite believing that sexual harassment policies were regarded as effective tools, few academic staff members received training on the utilization of the policy (Joubert et al., 2011; Bondestam \& Lundquvist, 2020). Research also suggests that most medical learners experience some form of harassment or discrimination and this high prevalence does not appear to be declining over time (Fnais, et al., 2014). Improving our understanding of the discourses in discrimination and harassment policies may provide useful insights to address such challenges.

Attention to policy discourses may also help deepen our understanding of how institutional policy discourse reflect organizational practices. Discourse refers to a set of statements or ways of thinking that regulate or influence how our social world is constructed and perceived (Kuper et al., 2013). In the context of discrimination or harassment policies, discourses are the tacit forces that shape the policy itself, and power remains a central force that inherently shapes which discourses gain legitimacy and which do not (Reckhow et al., 2021; Feindt \& Oels, 2005). Discourse can limit how policy language is enacted in the context of 
existing power relations, as well as mediate the role of specific social and political contexts (Foucault, 1972). For example, medical schools may use discourse to protect and reinforce their own power, thus placing the egalitarian ideals of discrimination or harassment policies in direct tension with the ways in which power relations are organized. How a medical school uses policy in response to discriminatory practices has direct implications for any effort to advance EDI. Therefore, in this study, we sought to explore the following research questions: (1) What are the dominant discourses in discrimination and harassment policies within Canadian faculties of medicine? (2) To what extent do these discourses reflect how discrimination or harassment is enacted on in practice?

\section{Methods}

To conduct this research, we were informed by critical discourse analyses (CDA) and previous writings authored by Michel Foucault and Kimberlé Crenshaw. Foucault notes that power is reflected in how discourse reinforces or diminishes social dominance, and that discursive notions are constructed within specific historical contexts for a variety of economic, social, and political reasons (Foucault, 1972; Hodges, et al., 2014). Seminal writings of Crenshaw draw from historical roots within critical disciplines to note that socially constructed identities are often treated as intrinsically negative frameworks in which "social power works to exclude or marginalize those who are different." (Crenshaw, 1991, 1989). Intersectionality therefore refers to an understanding that the human experience is uniquely shaped by the interaction of different identities within the context of power structures (Crenshaw, 1991). The processes of such interactions shape various forms of privilege and oppression that are interdependent (Crenshaw, 1991). When applied to the context of discrimination within academic medical organizations, intersectionality emphasizes that any inequities are the outcome of intersections between different social locations, power relations, and multiple overlapping social identities and experiences.

While both intersectionality and CDA seek to interrogate power relations and gain a deeper understanding of how language shapes practice, we chose to inform our study with the work of both Foucault and Crenshaw due to existing critiques of Eurocentric epistemologies that underpin how health professions education is understood and enacted (Paton et al., 2020). Incorporating intersectionality as an analytic concept within the knowledgepower analysis of Foucauldian CDA allowed us to explore how different social groups are represented and reflected in discrimination policies.

CDA allows for a critical examination of the origins of long-standing ideas and tracing the development of emerging ones. CDA methodology is a rigorous approach that has been effectively used within medical education research to systematically explore how language relates to social practice, knowledge, and power relations (Kuper \& Whitehead, 2013; Hodges et al., 2008; Rogers et al., 2005; Shaw \& Balyer, 2009; Whitehead, 2013; Haddara \& Lingard, 2013). In general, a CDA is a useful tool to question taken-for-granted assumptions and explore how language relates to the social construction of different concepts, while focusing on righting social wrongs and enacting social change. We defined discourse as a structured set of ideas that shape how policy is enacted into practice (Hodges et al., 2014). Overall, our approach sought to focus on how discourses shape practices while reflecting power asymmetries related to EDI within medical education. 
CDA requires gathering and studying an archive of texts that should reflect the social world the discourse is constructing. An archive refers to a collection of texts or materials that form the organization of the parts of a discourse (Foucault, 1978). The archive may include statements, objects, practices, and traditions. In this approach, discourse refers to what may constrain or enable writing, speaking, and thinking about a topic within a particular historical context (McHoul \& Grace, 1993).

We began by familiarizing ourselves through reading a broad range of sources and discussion and debate amongst the research team. We sought to assemble an initial archive that reflected policy that was publicly available and accessible for a medical learner, faculty, or staff member at a medical school. We assembled an archive of 22 texts consisting of publicly available discrimination and harassment policy documents in 13 Canadian medical schools that were active as of November 2019. Our initial archive consisted of higher education policy at a university level. We expanded our archive to include publicly available policies that related to discrimination that could occur within a clinical learning environment. Once we had assembled our archive, our analysis sought to combine the approach of a CDA with the core sensitizing concept of intersectionality.

Intersectionality calls for a deeper understanding of how multiple identities intersect at individual, sociocultural, and structural levels to perpetuate and further reinforce systems of oppression and privilege (Rosenthal, 2016). Common features of an intersectionalityinformed analysis include: (1) Recognition that multiple social categories are interconnected and cannot be understood without considering how they relate to one another (Bauer, 2014; Monrouxe, 2015; Shields, 2008). (2) Recognition of how power and inequality are interrelated, and (3) Recognition that social identities are influenced by historical contexts (Monrouxe, 2015; Bright et al., 2016; Christensen \& Jensen, 2012; Shields, 2008; Warner \& Shield, 2013). Similarly, Foucauldian-informed discourse analysis foregrounds both historicity and power relations by providing researchers with a set of principles that inform their analysis of text. When applied to the context of discrimination within academic medical organizations, both intersectionality and Foucauldian analysis provide a lens to understand and critically analyze how discourse shapes practice from both perspectives. For example, an intersectional analysis would explore whether discrimination policies foreground certain types of identity-based harassment, whether policy language reflects how history shapes power relations in the context of anti-Black or anti-Indigenous racism, or whether both power and social identity shape how academic medical organizations address complaints of discrimination or harassment.

To assist in the analysis, we developed a flexible set of guiding questions that sensitized members of the research team towards a critical analysis in the Foucauldian tradition (Table 1). Our initial set of questions related to Foucauldian analysis while interrogating the texts for intersectionality and how it was explicitly or implicitly related to policy discourse. Therefore, intersectionality informed each step of analysis while also informing a specific subset of analysis. Specific questions related to topics and themes in the texts, rhetorical strategies, problematization, and power relations. For example, questions asked which topics are present and absent, which discursive strands seem to be disconnected or entangled, what social values, subject positions, and social relations are constructed by the linguistic strategies employed, what is being problematized, what actors are mentioned in the text, and who is addressed as having the power to fix the outlined problem. We also asked who 
Table 1 - Analytic Framework for Critical Discourse Analysis informed by Intersectionality

\begin{tabular}{|c|c|}
\hline \multirow[t]{5}{*}{ Document } & Contextual data \\
\hline & Identified audience \\
\hline & Textual appearance \\
\hline & Who is the creator? \\
\hline & Features, headings, subheadings \\
\hline \multirow[t]{3}{*}{ Topics and themes } & What is present and what is absent? \\
\hline & How do topics relate to one another and overlap? \\
\hline & What discursive strands are connected or disconnected? \\
\hline \multirow[t]{6}{*}{ Rhetorical strategies } & What argumentation is used? \\
\hline & What logic underlies composition of text? \\
\hline & What allusions and metaphors are present or absent? \\
\hline & What are the references and sources of knowledge? \\
\hline & What characteristics, qualities, and attributes are assigned to the subject? \\
\hline & $\begin{array}{l}\text { What values, subject positions, and social relations are constructed by the } \\
\text { linguistic strategies? }\end{array}$ \\
\hline \multirow[t]{3}{*}{ Problematization } & What is being problematized and where is it localized? \\
\hline & Who has the power to fix the problem \\
\hline & What perspective does the text have about the future? \\
\hline \multirow[t]{4}{*}{ Power relations } & $\begin{array}{l}\text { Who is defining, identifying, and assessing the problem based on what informa- } \\
\text { tion and identities? }\end{array}$ \\
\hline & Which actors are mentioned in the text and how are they portrayed? \\
\hline & Which potential problems are silenced and how? \\
\hline & What solutions or suggestions are being made? \\
\hline \multirow{2}{*}{$\begin{array}{l}\text { Knowledge and } \\
\text { expertise }\end{array}$} & What forms of the knowledge does the text refer to? \\
\hline & Are there forms of knowledge that are absent, valued, or undervalued? \\
\hline \multirow[t]{5}{*}{ Intersectionality } & Is intersectionality present or absent? \\
\hline & How is intersectionality reflected in the text? \\
\hline & Does the text consider the dynamic and fluid nature of social identities? \\
\hline & Does the text consider how power and inequality is interrelated? \\
\hline & Does the text consider hos social identities are influenced by historical contexts? \\
\hline
\end{tabular}

appears to be defining, assessing, or identifying the problem, and what forms of knowledge are present, absent, valued, or undervalued in the text.

Within the team, the lead author (JS) independently read each text and completed analytic notes. Other team members reviewed at least 3 of the policy documents and each document was reviewed independently by at least 2 team members. The team came together at regular intervals to discuss findings and synthesize results. Discursive themes were discussed until consensus was achieved in an explicitly non-hierarchical way using constant comparative analysis.

Team composition included JS who identifies as a racialized cis-male, and who is a physician in practice as well as a PhD scientist in education. The study was conceptualized by JS who sought a deeper intersectional analysis consistent with the lived experience of working with racialized individuals in both clinical and educational contexts. HG is a medical social advocate, self-identifying as belonging to a religious minority and a former immigrant. She is combining her passion for innovation, leadership, and scholarship, the creation of tools, processes and advocacy for learners, patients, families, informing organizational changes. $\mathrm{AB}$ is a white woman and a PhD-trained medical education scholar interested in social accountability. She held recent roles as a staff member, learner, and faculty member at two 
Canadian medical schools, and throughout the analysis was mindful of how her perspectives were grounded in those of a learner due to personal and professional proximity to this group. WH is a clinician, administrator, and researcher with expertise in critical care and discourse analysis. As a white passing male who is nevertheless a member of a religious and cultural minority, he has experienced the "insider-outsider" effect and most closely associates with the identity of a tempered radical (Meyerson \& Scully, 1995). SR is a senior medical edu-

Table 2 - Synthesis of Competing Discourses Within Discrimination and Harassment Policies in Canadian Faculties of Medicine

\begin{tabular}{ll}
\hline Discourse & Idealizing Equity \\
\hline Concepts & Equity is central to an organizations \\
& value and mission. \\
& Equity is essential for achieving "insti- \\
& tutional excellence." \\
& Organizational climate should be free \\
& from discrimination. \\
& There is a shared responsibility for \\
& addressing discrimination among \\
& the organization and the individuals \\
& within.
\end{tabular}

Language We will "not tolerate" discrimination. Subordinating Equity

Preference for informal resolution of "credible" and "reasonable" allegations.

False allegations are worse than harassment or discrimination.

Freedom from discrimination should not interfere with freedom to express an opinion or idea. Organizations should prioritize respect, civility, and professionalism.

Objects created

$\begin{array}{ll}\begin{array}{l}\text { Power } \\ \text { relations }\end{array} & \text { Organization seeks to maintain ideal- } \\ & \text { ized version of reality. } \\ & \text { Organizations gain power through } \\ & \text { potential weaponization of civility and } \\ & \text { professionalism. } \\ & \text { Individuals and organizations have } \\ & \text { reciprocal power. }\end{array}$

Virtuous organization that champions values and principles related to equity. Organization proactively seeks to ensure individual members are free from experiencing discrimination.

Organizations as responsible for prevention and intervention.

Both individuals and organizations have agency to address the problem. Organizations perceived as "fair" and "neutral."

reciprocal power. Freedom from discrimination means an environment or climate that is "collegial" rather than "poisoned." The "University recognizes its institutional responsibility"

All members of the "University" have a "shared responsibility" for preventing and addressing discrimination.

Any problems should "resolved early" within at the "lowest possible level" through an "immediate and local approach."

Addressing the problem requires "implementing and respecting" the "values within the unique environment of the University" as a "delicate" task that "precludes the use of blunt instruments." Any allegations must not interfere with "reasonable expression of opinions, debate, or critique." A "respectful and inclusive organizational culture" is one that "upholds a fundamental commitment to freedom of expression."

"Unit heads bear the specific and primary responsibility for promoting an environment free from harassment."

The employee "bears the responsibility to report" discrimination or harassment in the workplace.
Organization is more credible than complainants whose credibility and reasonableness is questionable by default.

Organization as home of free and spirited debate and discourse.

Complainants as inherently threatening to values of organization.

Those experiencing discrimination are burdened with reporting it.

Those with structural power in organizations have authority to adjudicate what qualifies as discrimination.

Organizations and leaders fear losing power due to need to act on legislative mandate.

Organizations define and maintain professional ideals that may stifle attempts to report.

Power remains primarily with organizations and those with high status within the hierarchy. 
cator and researcher in equity, diversity, and inclusion in health professions education. He considers himself racialized and as belonging to a sexual minority in the Canadian context. In his critical reflexivity as a researcher on this project he has sought to be open about his status as an "insider" engaging in critical work, and as a person who has experienced the imperfections of the academic work environment firsthand. .

\section{Results}

We analyzed a total of 22 texts. Many of the documents in our archive included policies that were at a university level as there were limited policies specific to clinical or medical learning environments that were publicly accessible. In several instances there was specific policy for one aspect of education, such as postgraduate learning, but no publicly available policies specific to undergraduate learning, basic sciences, or faculty affairs.

We identified two dominant discourses, summarized in Table 2, and clear tensions between and within these discourses relating to our initial research question. In one discourse, equity was idealized and centered as a value for organizations. This discourse framed equity as a proactive endeavour on the part of the collective. In the other discourse, equity was subordinated under values of individual and academic freedom. This second discourse is in contrast to the first, diminishing equity while centering self-protection of the organization. The discursive tension between both suggests that despite idealizing equity, organizations are more likely to fall into a default mode of self-protection, particularly during times of stress or strain. Therefore, the overall discursive effects of policy language seek to maintain a system where power remains with the powerful, thus diminishing agency and power for those who experience discrimination. The sections below provide examples of how these discourses reveal themselves within the policy texts and documents.

\section{Idealizing equity while centering institutional self-protection}

We found that policies clearly valued certain discourses as explicitly important, yet there were conflicting discourses that were in tension with what was explicitly shared. Almost all policies tended to idealize equity while suggesting that organizations required such policies to protect themselves in accordance with existing obligations such as human rights codes and occupational health and safety legislation. An example is Manitoba's Respectful Work and Learning Environment policy where it was explicitly stated on the first page that the reason for their policy is to "promote and support a respectful work and learning environment and ensure compliance with relevant legislation." Almost all policies referred to existing human rights legislation, occupational health and safety legislation. In addition, several policies referenced jurisdiction specific legislation and regulation, referencing discrimination as contrary to prescribed regulation/legislation in their particular jurisdiction or province.

The tension between idealizing equity while placing limits on enacting equitable policies was also exemplified by language promoting early resolution when discrimination and harassment were alleged by complainants (individuals within the institution who pursue a discrimination and/or harassment complaint), and by foregrounding consequences for false allegations. For example, Saskatchewan advocated for "informal resolution" through discussion, while Memorial suggested that any problems should be dealt with at the "low- 
est possible level" through an "immediate and local approach," while using terms such as "vexatious...frivolous...malicious" when describing the potential for false allegations and consequences for such accusations.

Overall, discursive tensions were revealed between the idealization of equity and the process of managing complaints, with an overall tendency towards informal and rapid processes of resolution. Such tensions created a binary between serving equity and minimizing the official nature of organizational processes, which served to place equity as the hierarchically inferior object within the binary. Organizations privileged equity yet indicated that protection can be better achieved by perfunctory and superficial treatment of complaints rather than proactive engagement. There were several instances of explicit policy language referring to a threshold for responding to extreme instances of harassment and discrimination without describing explicit or extreme actions that organizations can take.

Several different policies spoke of a dedication and commitment to equity as part of an organization's values. For example, McGill University declared that, "the University recognizes that such excellence can only flourish in an equitable environment," while Alberta stated that they are a "leading teaching and research institution" that is "responsive to the needs of a diverse student population and workforce," and is "enriched by diversity.... and seeks to include many voices." However, several policies also included idealized rhetoric without examples of how to achieve this ideal. Memorial University's policy on intimidation and harassment for postgraduate learners provided an example of the tension between values of equity and excellence. The statement initially stated, The Faculty of Medicine of Memorial University values the dignity and self-esteem of every staff member, patient, volunteer and student and promotes a respectful workplace. Every member of the medical community associated with the Faculty has the right to study, work and conduct his or her activities in an environment free of unlawful and/or inappropriate discrimination and harassment.

Yet later stated that "Harassment does not include...insistence on academic excellence... (or) situations that involve appropriate directions of the...corporation...(or).the statement of any opinion by a person who has been legitimately asked to state their opinion." Similarly other policies included language about "not tolerating" discrimination and harassment while limiting how organizations can respond when discrimination or harassment occur. For example, Ottawa's policy explicitly deferred to collective labor agreements noting, "this policy does not supersede existing collective agreement provisions."

Another example of discursive tension related to how policies appeared to problematize concepts such as credibility, reasonability, and normalcy. For example, Manitoba, Calgary, and Memorial invoked the concept "reasonability" when discrimination or harassment was alleged to occur. Both Memorial and Calgary suggested in their definition of harassment that a person would only "reasonably know" that their conduct was offensive, while Manitoba mentioned "reasonable" 6 times in 11 pages while both Manitoba and Calgary stated that evidence of harassment must be "credible." Limitations were also placed on what constitutes discrimination and harassment. Several policies explicitly stated that discrimination and harassment did not include a "normal" exercise of management or evaluation, or "normal supervisory responsibilities" such as "day to day management, demands of academic excellence or reasonable quality of work" (Saskatchewan) or "appropriate assessment" or "reasonable communication of expectation of quality of academic performance." (Queens). 
The use of language such as "normal" can be problematic as institutions get to define what normal means. Some relied on existing policy, legislation, and regulation outside of the academic setting to describe what constitutes discrimination and harassment. Such concepts are also socially constructed by dominant social identities and can be weaponized against marginalized individuals. When viewed through the lens of a potential complainant, discourses on credibility, reasonability, and normalcy may remove power and agency from individuals who are structurally vulnerable within academic institutions.

\section{Freedom from discrimination versus academic freedom}

Discrimination and harassment policies demonstrated a tension between discourses on freedom and emancipation. Although several policies described the need to create workplace and learning environments that were "free" from discrimination and harassment, they also explicitly spoke of the need to ensure academic freedom. These two discourses created significant tension that appeared difficult to reconcile due to a lack of clarity regarding how either freedom from discrimination or free academic study were defined.

There were several examples of how both discourses on freedom were conflictual with one another, creating yet again, another binary pair. In the Northern Ontario School of Medicine's policy, the word "free" first appeared in the preamble referring to the organization's commitment to "an environment free from prohibited discrimination and harassment," yet in the very next paragraph stateed that the same organization is,... also committed to vigilance in protecting academic freedom, including the rights of freedoms of expression, inquiry and research and recognizes that academic excellence and academic freedom can only be achieved when there is freedom to work, teach, research and learn in an environment in which discrimination and harassment are not tolerated.

Similarly, the University of British Columbia policy described "freedom from discrimination" while emphasizing the need for individuals to be "free to criticize." While Queens stated, "...discussion and debate about controversial topics in an academic environment, do not fall into the category of harassment." Similarly, the University of Toronto stated that "freedom from harassment" required "implementing and respecting" the "values within the unique environment of the University" as a "delicate" task that "precludes the use of blunt instruments."

Definitions of both types of freedom tended to be vague. For example, Manitoba described freedom from discrimination and harassment as a "collegial and conducive" environment where "discrimination will not be condoned. There were multiple references to a respectful" or "positive climate," (Saskatchewan) which was the opposite of a "poisoned" one (McMaster). In terms of academic freedom, the University of British Columbia stated that academic freedom was, "freedom of thought, belief, opinion and expression" which carries an expectation that University members "will conduct themselves in a responsible manner so as not to cause, condone or participate in the Discrimination of another person or group of persons." They went on to state,

"Academic Freedom is a fundamental tenet of ... [and] includes the right to engage in free and full discussion, not only of ideas that are safe and accepted, but of those which may be unpopular and even abhorrent, and to make statements, assign readings 
or use instructional techniques that challenge and may even offend the sensibilities, ideas and beliefs of others."

Only Alberta placed limits on what could be constituted as academic freedom by noting that "academic freedom, however, is not without limits. It is not, for example, a justification or license for discrimination or harassment."

Discourse on academic freedom was also intertwined with discourses on "professionalism" and "civility." Some discursive strands described harassment and discrimination as "unprofessional," (Dalhousie) while others framed individual behaviour related to the construct of professionalism in potentially problematic ways. In one such instance, discourse positioned professionalism as an "academic requirement" for members of the organization (Ottawa). In another, there was also language describing the need for a "respectful" workplace without defining what such a workplace actually means (Memorial). There may be discursive effects related to such discourses that reinforce the weaponization of professionalism and civility to stifle reporting.

\section{Conflicting discourses on responsibility for addressing discrimination and harassment}

There was a central tension between which actors were responsible for discrimination and harassment, and which were responsible for addressing it. Several statements described a discourse of "shared responsibility" to address discrimination and harassment and maintaining a respectful climate. Yet, there was discursive conflict between such discourses with the idea that the power to act on discrimination rests within the power structures of institutions, rather than those who experience discrimination such as complainants.

Almost all policies were created by governing structures within higher education without any explicitly stated input from other groups within the organization. Several policies implied that responsibility to speak up about the problem of discrimination lied with the victim. Such policies tended to problematize harassment/discrimination at an individual level, rather than within the organization itself.

The discourses that appeared to balance individual rights and institutional responsibilities were explicit in their language. For example, McGill, Alberta, and McMaster put a particular onus on those "in positions of academic and administrative authority" and several others emphasized a "statement of responsibility" to take "reasonable action" for both prevention and intervention. Such policies also specified that harassment and discrimination are both an individual and structural problem, referring to "systemic institutional practices and policies," and emphasized the role of organizations and senior leaders to promote awareness of discrimination or harassment through education and proactive measures. Alberta's policy stated that the "University recognizes its institutional responsibility" and "Senior Leaders have administrative responsibility" without providing any specific details or further elaboration on how such responsibility would be enacted.

In other instances, policy discourse spoke of balancing individual rights and institutional responsibility through distancing organizational actors and external investigators, yet explicitly noted that the power to grant or deny appeal lied within the role of a Dean. Arm's length actors that were not truly third parties or external to the organization such as equity advisors were delegated a role in triaging complaints, mediating conflict, and resolving disputes. Such actors appeared to have limited power to repair or resolve structural issues. 
In general, policies that were specific to medical education seemed to give more power to those in positions of authority than general university policies, which tended to include descriptions of "fair," "objective," and "neutral" adjudication without recognition of power differentials and imbalances between those who report harassment/discrimination and those with structural power within organizations (McGill).

\section{Intersectionality largely absent}

Intersectionality was largely absent from the policy discourse we analyzed. Where intersectionality was present, it was not explicitly articulated in relation to the theoretical and methodological underpinnings of the concept of intersectionality rooted in critical social science literature. Instead, such policies referred to intersecting definitions of discrimination in accordance with language from legal policy within their jurisdiction. For example, Saskatchewan's policy explicitly included discrimination related to religion, creed, marital status, family status, gender expression, gender identity, two spirit identity, sexual orientation, disability, age, colour, ancestry, nationality, place of origin, race or perceived race and receipt of public assistance. Only Alberta's policy specifically mentioned "racial harassment" as a unique form of harassment. Even when different forms of discrimination were mentioned, they were considered distinct from one another without consideration for how they interact with one another, and sometimes with dated or antiquated phrasing. Dalhousie's policy also included protection from discrimination based on "political belief," raising questions of how competing discourses of discrimination would be addressed.

Among the policy we analyzed, several organizations foregrounded gender-based harassment and discrimination without mentioning other forms of discrimination. For example, the University of Toronto's policy explicitly did not refer to gender-based harassment because the organizations had a distinct policy unique to sexual harassment. Memorial 's policy included four examples of harassment yet the content in the human rights section for sexual harassment and racial/ethnic harassment was much longer than the sections relating to sexual minorities and people with disabilities.

\section{Discussion}

Our analysis of discrimination policies identified several discourses in conflict with one another. Idealization of equity appeared to be in tension with self-protection, freedom from discrimination was in tension with academic freedom, and shared responsibility for preventing and addressing discrimination was in tension with a discourse of individual responsibility. Clear binaries were created with each having a hierarchically superior pole, and with the overall effect that such policies privileged the interests of institutions to change as little as possible, to address concerns as perfunctorily as possible, and placing heavy onus and reporting risk on individuals who are targets of harassment and discrimination, to stifle them from reporting their experience. The overall discursive effects appeared to worsen power asymmetry, positioning organizations and individuals with structural power as having more agency than complainants who experience discrimination. 


\section{Reinforcing power while diminishing agency}

Overall, policy discourse emphasizes that power remains with the powerful. Policies appear to uphold the ideal of a virtuous organization that is free from discrimination. These discourses conflict with the idea that such organizations have created policy due to legislative or regulatory requirements, rather than for the purposes of creating inclusive environments where diverse individuals are comfortable expressing their social identities. In such contexts, policy language serves to protect organizations and the powerful individuals within them. This finding is unsurprising given academic medicine's longstanding history of oppressing minoritized social groups while elevating dominant ones (Smedley, et al., 2003; Gravlee \& Sweet, 2008; Seabrook \& Wyatt-Nichol, 2016; Boatright et al., 2017; Edmond et al., 2001). In the context of increased attention to addressing equity and anti-racism, it remains to be seen if academic organizations will align with legislative and regulatory bodies in perpetuating stigma and bias towards minority and fragile groups, or work to dismantle inequities experienced by the individuals in the academic community.

Another example of how policy discourse reinforce institutional power comes from our finding related to academic freedom. Discourses on academic freedom are intrinsic to the academy as a resistive force, yet, in the case of discrimination and harassment policy, academic freedom is invoked as a limitation to achieving equity and inclusion. The construction of academic freedom as absolutist is one of the major ways that it is weaponized. It has never been absolutist, and there are many examples of non-hegemonic thinking being stifled in the academy. Any such constructs cannot be divorced from knowledge power relationships.

The burden on reporting remains with those who are the victims of harassment and discrimination. Such individuals are positioned as having less agency while encumbered with having to legitimize the credibility of their lived and living experiences. Placing a disproportionate onus of responsibility on those who experience discrimination to legitimize their experience has the potential to erode self-esteem and worsen stereotype threat which adversely influences learning and psychological well-being (Jost \& Hunyady, 2003), as well as to diminish reporting.

As a consequence, the power to investigate and define key terms remains within the organization itself. This creates a self-perpetuating cycle where organizational leaders can protect their own power rather than pursue a more egalitarian power structure. Even in circumstances where external adjudicators were involved, many medical schools sought to maintain decision-making authority within senior administrative leaders, rather than thirdparty investigators. Further, perpetrators of discrimination have an assumption of ignorance and are presumed to not know the difference between what may be inappropriate versus unacceptable. They can therefore justify discriminatory acts by invoking good intentions.

In addition, we found organizations sought to solve their internal problems from within without considering transparency or public reporting. There was little evidence of any participatory approaches to policy development or revision. Language was often outdated, and little to no policies included mandatory reporting so that individuals who experienced discrimination could hold organizations accountable for their practices. 


\section{Implications for perceiving and reporting discrimination}

The discursive effects of discrimination policies create the object of a complainant as inherently disruptive or threatening to the values and ideals of medical organizations. Existing policy discourse may reinforce the idea that academic medicine is a controllable enterprise where individuals receive what they deserve. This ideal maintains the concept of meritocracy where organizations perceive themselves as having and expecting preferential treatment, thus perceiving reporting of discrimination as an inherent threat (Major, 2014; Watson, 2017).

Policy language on respect, weaponizing civility, and professionalism suggests that concepts such as professionalism and academic freedom have the potential to be weaponized by organizations to maintain hegemonic power. Existing definitions of professionalism in medicine are often equated with subservience to hierarchical norms. Those with structural power within organizations have the simultaneous privilege of being able to define vague terms and evaluating others on the basis of their own definition (Brainard and Brislen, 2007). Historically, members of groups who tend to experience discrimination have disproportionately been tasked with both suffering from and fighting against discrimination in medical education (Watson, 2017; Cyrus, 2017; Grissom et al., 2015).

Academic medical contexts where reporting discrimination is perceived as threatening, and where there is a tendency to fall into minimization and denialism may hinder reporting of discrimination for members of low-status social groups (Kaiser \& Major, 2006). Historically, most individuals who perceive discrimination tend to keep their experience to themselves (Cortina, 2004). This is often due to the perceived consequences of reporting such as fearing being perceived as a troublemaker (Kasier \& Miller, 2004) or retaliation (Feagin \& Sikes, 1994). In a survey of medical students in the United Kingdom, two-thirds of participants had experienced or witnessed one type of discrimination or harassment, yet only 5\% had reported incidents as reporting was perceived as ineffective and potentially victimizing for the reporter (Broad, et al., 2018).

\section{Implications for the future}

Our findings related to discursive tensions suggests a fundamental discrepancy between policy and practice as it pertains to issues of equity in academic medicine. It is possible that any discourses regarding equity are resistive to existing power dynamics which tend to foreground self-protection and academic freedom. These tensions raise questions if equity can be achieved through policy discourse alone or if more substantive structural transformation is necessary. We would argue that the proliferation of organizational commitments to addressing issues such as racism and sexism in their midst will ring hollow unless transformational change occurs for both individuals and organizations (Hess, et al., 2020). Such change requires more than education or training, it requires revising existing policy language to facilitate more egalitarian practices that diminish power differential, rather than magnifying them.

One such practice would involve participatory co-design of future policy. Our findings suggest that a community-engaged participatory approach to developing future policy should include communities of interest, advocacy groups, individuals who have lived/living experience of discrimination, and non-academic partners. Participatory approaches are 
widely implemented in research and knowledge mobilization (Welton \& Mansfield, 2020; Michels \& De Graaf, 2010; Kothari \& Wathen, 2017). Such approaches can foster trust, improve policy, and enhance power-sharing across traditional asymmetries.

Along with others, we would also suggest that addressing such power differential requires teaching future physicians about their power with respect to legal and policy environments including the basics of public policy and processes of policy change (Kuper et al., 2017). Our findings the power remains with the powerful when it comes to policy discourse related to discrimination highlights that existing mechanisms in higher education are insufficient to foster meaningful change unless power is shared, rather than hoarded (Hess et al., 2020). A structural approach (Bailey et al., 2017) that emphasizes changes in both policy and practice (Raj et al., 2019) is necessary for academic medical organizations to truly advance equity, diversity, and inclusion towards a future where the academy can fulfill its role as an agora of ideas colliding between different actors, transmuting to new ones through the collisions, and transforming the actors towards emancipatory knowledge.

\section{Conclusions}

Our research revealed that discrimination and harassment policy discourse allowed for power to be maintained and controlled by those in power. The burden on reporting discrimination or harassment remains with the complainant who experiences discrimination. This work demonstrates how furthering equity within academic medicine may be challenging through the use of policy discourse alone and may require a more fundamental structural transformation. Given the resistive and emancipatory nature of discourse on equity, we must engage individuals who experience discrimination and harassment in the design and evaluation of future policy to advance equity, diversity, inclusion in a meaningful way.

\section{References}

Bailey, Z. D., Krieger, N., Agénor, M., Graves, J., Linos, N., \& Bassett, M. T. (2017). Structural racism and health inequities in the USA: evidence and interventions. Lancet, 389, 1453-1463

Bauer, G. R. (2014). Incorporating intersectionality theory into population health research methodology: challenges and the potential to advance health equity. Social science \& medicine, 110, 10-17

Bondestam, F., \& Lundquvist, M. (2020). Sexual harassment in higher education - a systematic review. European Journal of Higher Education, 10, 397-419

Boatright, D., Ross, D., O’Connor, P., Moore, E., \& Nunez-Smith, M. (2017). Racial disparities in medical student membership in the Alpha Omega Alpha Honor Society. JAMA Internal Medicine, 177, 659-665

Brainard, A. H., \& Brislen, H. C. (2007). Viewpoint: learning professionalism: a view from the trenches. Academic medicine: journal of the Association of American Medical Colleges, 82(11), 1010-1014

Bright, L. K., Malinsky, D., \& Thompson, M. (2016). Causally interpreting intersectionality theory. Philosophy of Science, 83(1), 60-81

Broad, J., Matheson, M., Verrall, F., Taylor, A. K., Zahra, D., Alldridge, L., \& Feder, G. (2018). Discrimination, harassment and non-reporting in UK medical education. Medical Education, 52, 414-426

Bullock, J. L., Lockspeiser, T., del Pino-Jones, A., Richards, R., Teherani, A., \& Hauer, K. E. (2020). They Don't See a Lot of People My Color: A Mixed Methods Study of Racial/Ethnic Stereotype Threat Among Medical Students on Core Clerkships (95 vol., pp. S58-66). Academic Medicine

Canadian Medical Association (2020). Background to CMA Policy: Equity and Diversity in Medicine. https://policybase.cma.ca/documents/Policypdf/PD20-02s.pdf

Christensen, A. D., \& Jensen, S. Q. (2012). Doing intersectional analysis: Methodological implications for qualitative research. NORA-Nordic Journal of Feminist and Gender Research, 20(2), 109-125 
Cortina, L. M. (2004). Hispanic perspectives on sexual harassment and social support. Personality and social psychology bulletin, 30(5), 570-584

Crenshaw, K. (1989). Demarginalizing the Intersection of Race and Sex: A Black Feminist Critique of Antidiscrimination Doctrine, Feminist Theory and Antiracist Politics. University of Chicago Legal Forum, $1(8)$

Crenshaw, K. (1991). Mapping the Margins: Intersectionality, Identity Politics, and Violence against Women of Color. Stanford Law Review, 43(6), 1241-1299

Cyrus, K. D. (2017). Medical education and the minority tax. Jama, 317, 1833-1834

Fnais, N., Soobiah, C., Chen, M. H., Lillie, E., Perrier, L., Tashkhandi, M. ... Tricco, A. C. (2014). Harassment and discrimination in medical training: a systematic review and meta-analysis. Academic Medicine, $89,817-827$

Edmond, M. B., Deschenes, J. L., Eckler, M., \& Wenzel, R. P. (2001). Racial bias in using USMLE step 1 scores to grant internal medicine residency interviews.Academic Medicine, 76,1253-1256

Feagin, J. R., \& Sikes, M. P. (1994). Living with racism: The black middle-class experience. Beacon Press

Feindt, P. H., \& Oels, A. (2005). Does discourse matter? Discourse analysis in environmental policy making. Journal of Environmental Policy and Planning, 7(3), 161-173

Foucault, M. (1972). The Archaeology of Knowledge and the Discourse on Language, trans. AM Sheridan Smith (New York: Pantheon, 1972), 129

Foucault, A. (1978). The history of sexuality. New York: Pantheon Books

Gravlee, C. C., \& Sweet, E. (2008). Race, ethnicity, and racism in medical anthropology, 1977-2002. Medical anthropology quarterly, 22(1), 27-51

Grissom, J. A., Kern, E. C., \& Rodriguez, L. A. (2015). The "representative bureaucracy" in education: Educator workforce diversity, policy outputs, and outcomes for disadvantaged students. Educational Researcher, 44(3), 185-192

Haddara, W., \& Lingard, L. (2013). Are we all on the same page? A discourse analysis of interprofessional collaboration. Academic Medicine, 88(10), 1509-1515

Hess, L., Palermo, A. G., \& Muller, D. (2020). Addressing and Undoing Racism and Bias in the Medical School Learning and Work Environment. Academic medicine: journal of the Association of American Medical Colleges, 95(12S), S44-S50

Hodges, B. D., Kuper, A., \& Reeves, S. (2008). Discourse analysis. British Medical Journal, 337, 879

Hodges, B. D., Martimianakis, M. A., McNaughton, N., \& Whitehead, C. (2014). Medical education... meet Michel Foucault. Medical education, 48(6), 563-571

Jones, T., \& Nichols, A. (2020). Hard truths: Why only race-conscious policies can fix racism in higher education

Jost, T. J., \& Hunyady, O. (2003). Antecedent and Consequences of System-Justifying Ideologies (14 vol., pp. 260-265). American psychological Society5

Joubert, P., Van Wyk, C., \& Rothmann, S. (2011). The effectiveness of sexual harassment policies and procedures at higher education institutions in South Africa. SA Journal of Human Resource Management, 9,10

Kaiser, R. C., \& Miller, T. C. (2004). A stress and coping perspective on confronting sexism. Psychology of women quarterly, 28(2), 168-178

Kaiser, R. C., \& Major, B. (2006). A social psychology perceptive on perceiving and reporting discrimination. Law and Social Inquiry, 31(4), 801-830

Khazanchi, R., Crittenden, F., Heffron, A. S., Manchanda, C., Sivashanker, E. C., K., and, \& Maybank, A. (2021). Beyond Declarative Advocacy: Moving Organized Medicine And Policy Makers From Position Statements To Anti-Racist Praxis. Health Affairs Blog, 0. https://doi.org/10.1377/ hblog20210219.107221/fullhttps://www.healthaffairs.org/do/

Kothari, A., \& Wathen, C. N. (2017). Integrated knowledge translation: digging deeper, moving forward. $J$ Epidemiol Community Health, 71(6), 619-623

Kromydas, T. (2017). Rethinking higher education and its relationship with social inequalities: past knowledge, present state and future potential. Palgrave communications, 3(1), 1-12

Kuper, A., \& Whitehead, C. (2013). The practicality of theory. Academic medicine: journal of the Association of American Medical Colleges, 88(11), 1594-1595

Kuper, A., Whitehead, C., \& Hodges, B. D. (2013). Looking back to move forward: using history, discourse and text in medical education research: AMEE guide no. 73. Medical Teacher, 35, e849-860

Kuper, A., Veinot, P., Leavitt, J., Levitt, S., Li, A., Goguen, J. ... Whitehead, C. R. (2017). Epistemology, culture, justice and power: non-bioscientific knowledge for medical training. Medical education, 51(2), $158-173$ 
Major, A. (2014). To bully and be bullied: harassment and mistreatment in medical education. AMA Journal of Ethics, 16, 155-160

McHoul, A., \& Grace, W. (1993). A Foucault Primer (p. 31). (Taylor and Francis)

Meyerson, D. E., \& Scully, M. A. (1995). Crossroads tempered radicalism and the politics of ambivalence and change. Organization Science, 6(5), 585-600

Michels, A., \& De Graaf, L. (2010). Examining citizen participation: Local participatory policy making and democracy. Local Government Studies, 36(4), 477-491

Monrouxe, L. V. (2015). When I say? intersectionality in medical education research.Medical education, $49(1), 21-22$

National Academies of Sciences, Engineering, and Medicine (2018). Sexual harassment of women: climate, culture, and consequences in academic sciences, engineering, and medicine

Orom, H., Semalulu, T., \& Underwood, I. I. I. W. (2013). The social and learning environments experienced by underrepresented minority medical students: a narrative review. Academic Medicine, 88, 1765-1777

Pacific University Oregon. (n.d.). Equity, Diversity and Inclusion Glossary of Terms. Equity, Diversity and Inclusion Glossary of Terms. Retrieved April 22 (2021). from https://www.pacificu.edu/life-pacific/ support-safety/office-equity-diversity-inclusion/edi-resources/glossary-terms

Paton, M., Naidu, T., Wyatt, T. R., et al. (2020). Dismantling the master's house: new ways of knowing for equity and social justice in health professions education. Advances in Health Science Education, 25, 1107-1126

Perry, S. P., Hardeman, R., Burke, S. E., Cunningham, B., Burgess, D. J., \& van Ryn, M. (2016). The impact of everyday discrimination and racial identity centrality on African American medical student wellbeing: a report from the medical student CHANGE study. Journal of racial and ethnic health disparities, 3, 519-526

Price, E. G., Gozu, A., Kern, D. E., Powe, N. R., Wand, G. S., Golden, S., \& Cooper, L. A. (2005). The role of cultural diversity climate in recruitment, promotion, and retention of faculty in academic medicine. Journal of general internal medicine, 20(7), 565-571

Raj, A., Kumra, T., Darmstadt, G. L., \& Freund, K. M. (2019). Achieving Gender and Social Equality: More Than Gender Parity Is Needed. Academic Medicine, 94, 1658-1664

Reckhow, S., Tompkins-Stange, M., \& Galey-Horn, S. (2021). How the Political Economy of Knowledge Production Shapes Education Policy: The Case of Teacher Evaluation in Federal Policy Discourse (p. 01623737211003906). Educational Evaluation and Policy Analysis

Rodríguez, J. E., Campbell, K. M., \& Pololi, L. H. (2015). Addressing disparities in academic medicine: what of the minority tax? BMC Medical Education, 15, 1-5

Rogers, R., Malancharuvil-Berkes, E., Mosley, M., Hui, D., \& O’Garro, J. (2005). Critical discourse analysis in education: a review of the literature. Review of Education Research, 76, 35

Rosenthal, L. (2016). Incorporating intersectionality into psychology: An opportunity to promote social justice and equity. American Psychologist, 71(6), 474

Ross, P. T., Lypson, M. L., Byington, C. L., Sánchez, J. P., Wong, B. M., \& Kumagai, A. K. (2020). Learning from the past and working in the present to create an antiracist future for academic medicine. Academic Medicine, 95, 1781-1786

Seabrook, R., \& Wyatt-Nichol, H. (2016). The ugly side of America: Institutional oppression and race. Journal of Public Management and Social Policy, 23, 20-46

Shaw, S. E., \& Bailey, J. (2009). Discourse analysis: what is it and why is it relevant to family practice? Family Practice, 26, 413-419

Sheehan, K. H., Sheehan, D. V., White, K., Leibowitz, A., \& Baldwin, D. C. (1990). A pilot study of medical student "abuse". Student perceptions of mistreatment and misconduct in medical school. JAMA, 263, 533-537

Shields, S. A. (2008). Gender: An intersectionality perspective. Sex roles, 59(5), 301-311

Smedley, B. D., Stith, A. Y., \& Nelson, A. R. (2003). The healthcare environment and its relation to disparities. (In: Unequal Treatment: Confronting Racial and Ethnic Disparities in Health Care. Washington, DC: National Academies Press

Warner, L. R., \& Shields, S. A. (2013). The intersections of sexuality, gender, and race: Identity research at the crossroads. Sex roles, 68(11), 803-810

Watson, W. (2017). Against the odds: Blacks in the profession of medicine in the United States. (Routledge)

Welton, A., \& Mansfield, K. C. (2020). More than Just an Academic Exercise: Conjoining Critical Policy Analysis and Community-Engaged Research as an Embodiment of Political Action. Educational Studies, 56(6), 619-635

Whitehead, C. (2013). Scientist or science-stuffed? Discourses of science in North American medical education. Medical Education, 47, 26-32 
Publisher's Note Springer Nature remains neutral with regard to jurisdictional claims in published maps and institutional affiliations.

\section{Authors and Affiliations}

\section{Javeed Sukhera' $\cdot$ Helly Goez ${ }^{1,2} \cdot$ Allison Brown ${ }^{1,3} \cdot$ Wael Haddara ${ }^{1,4}$. Saleem Razack ${ }^{1,5}$}

Javeed Sukhera

javeedsukhera@gmail.com

1 Chair/Chief of Psychiatry, Institute of Living, Hartford Hospital, Terry Building, 200 Retreat Avenue, 06102 Hartford, Connecticut, USA

2 Department of Pediatrics, Faculty of Medicine and Dentistry, College of Health Sciences University of Alberta, Edmonton, Canada

3 Department of Medicine, Cumming School of Medicine, University of Calgary, Calgary, Canada

4 Department of Medicine and Centre for Education Research and Innovation, Schulich School of Medicine and Dentistry, Western University, Ontario, Canada

5 Department of Paediatrics and Institute for Health Sciences Education, McGill University, Montreal, Canada 